Fig. 28A
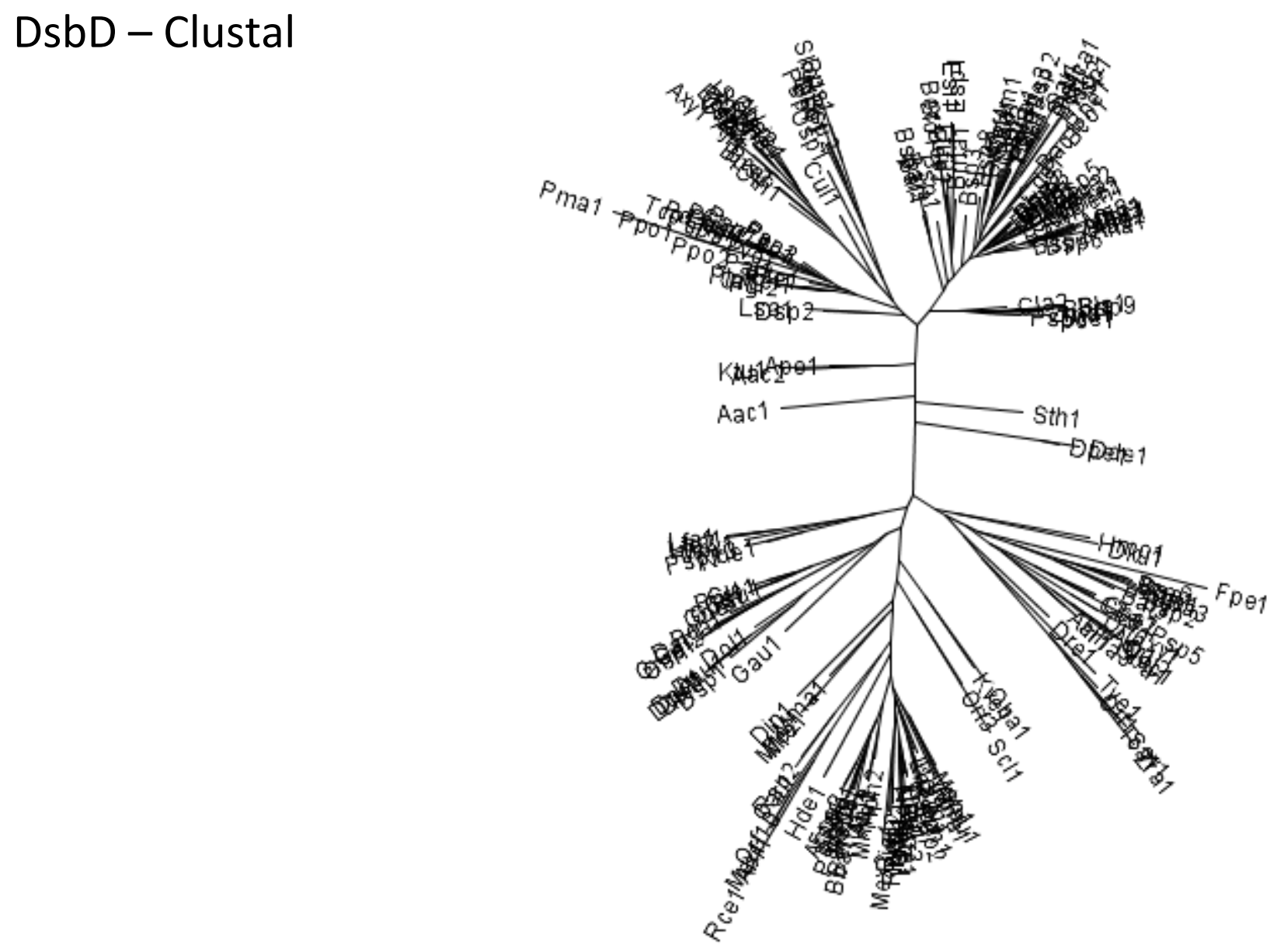
Fig. 28B

DsbD - Mafft

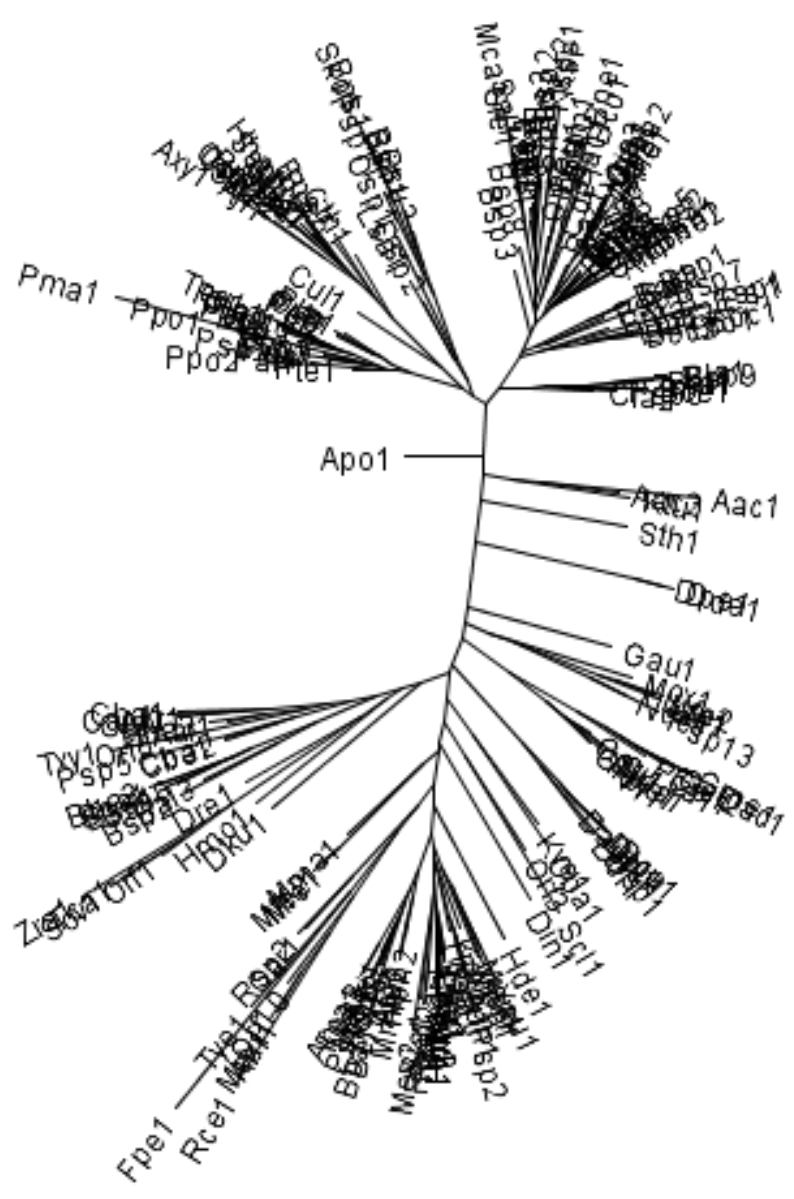


Fig. 28C

\section{DsbD - ProbCons}

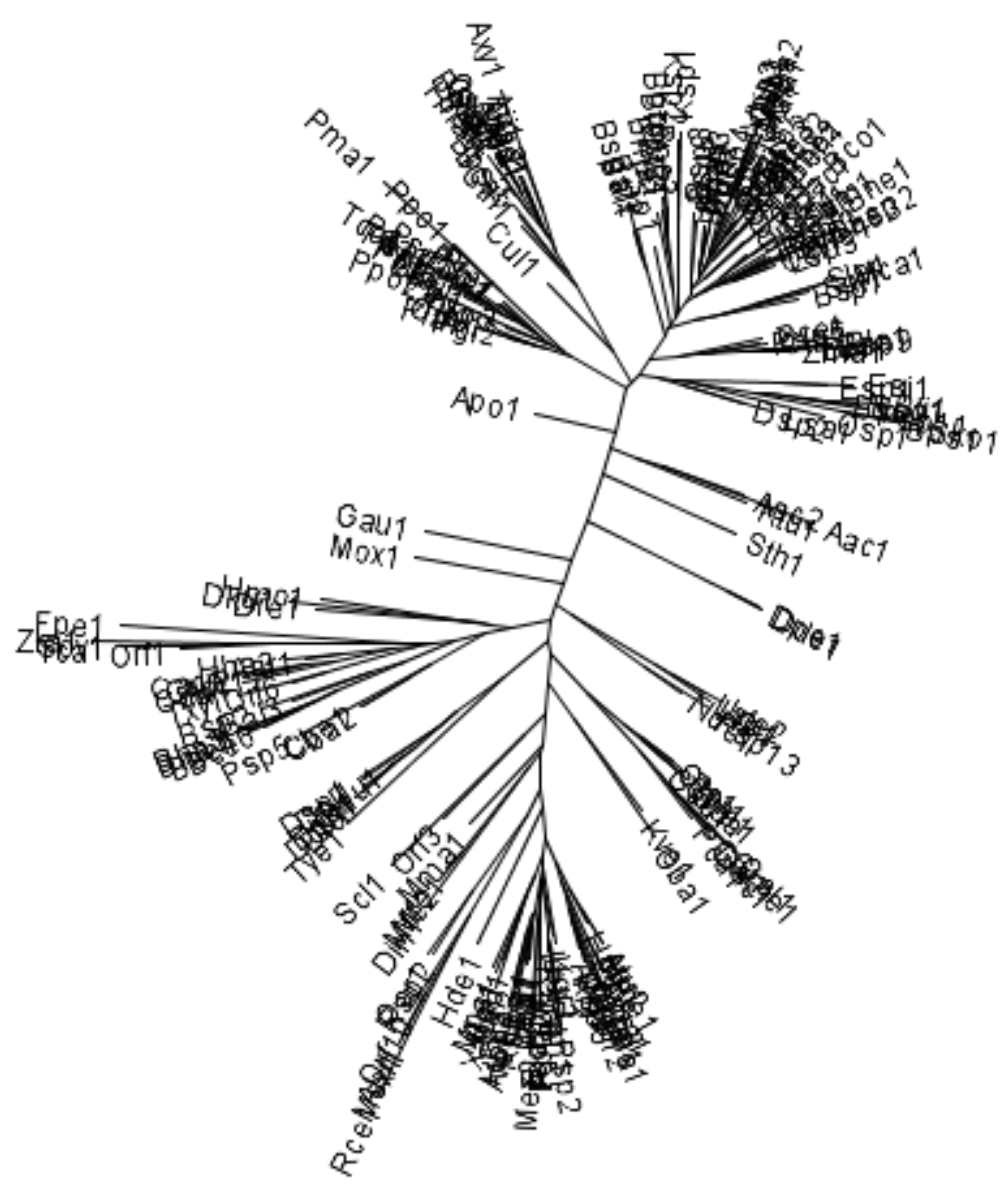

